\title{
From the Head Office
}

${ }^{1}$ Srinivasan MR, ${ }^{2}$ Meenakshisundaram Rajasekaran

How to cite this article: Srinivasan MR, Rajasekaran M. From the Head Office. J Oper Dent Endod 2016;1(1):2.

With great pride and privilege, we take this opportunity to thank the editorial team of Journal of Operative Dentistry and Endodontics (JODE) for their relentless efforts and implacable dedication to bring out its first issue of An Official Publication of Conservative Dentistry and Endodontics Association of Tamil Nadu (CEAT).

Conservative Dentistry and Endodontics Association of Tamil Nadu was started on 2nd October 2013, with the sole motto of conglomerating the scientific knowledge and to put to good purpose, the camaraderie and brotherhood of our fellowmen.
The association has a multifarious face, from the doyens of this discipline to the young budding endodontists. Within 3 years of its inception, it now boasts of a galactic membership, which is a no mean feat. We thank each and every one of you who have reposed their faith in the CEAT family. With due respect, we promise to serve our fraternity better which impels us to expand our horizons to reach further heights... .

Wishing you all the best in 2016.

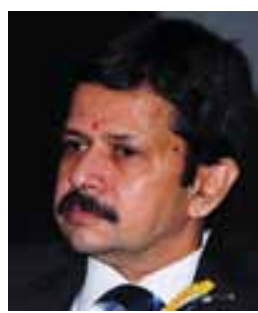

Srinivasan MR

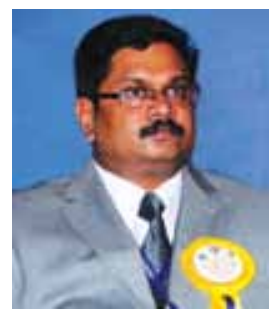

Meenakshisundaram Rajasekaran

${ }^{1}$ President, ${ }^{2}$ Honorary Secretary

${ }^{1,2}$ Conservative Dentistry and Endodontics Association of Tamil Nadu, Chennai, Tamil Nadu, India 